\title{
Hubungan Kegiatan Rohis Dengan Perilaku Sosial Peserta Didik Di SMA N 2 Puding Besar
}

\author{
Beldi Akbar'1, Basri², Dian Puspita Eka Putri ${ }^{3}$ \\ 1IAIN Syaikh Abdurrahman Siddik \\ 2IAIN Syaikh Abdurrahman Siddik \\ ${ }^{3}$ IAIN Syaikh Abdurrahman Siddik
}

\begin{tabular}{l}
\hline Info Artikel : \\
\hline Diterima 3 Januari 2020 \\
Direvisi 12 Januari 2020 \\
publikasikan 22 Januari2020
\end{tabular}

\section{Kata Kunci: \\ Rohis \\ Prilaku Sosial}

Keywords:

Rohis

Social Behavior

\begin{abstract}
ABSTRAK
Diambilnya masalah ini berdasarkan pertimbangan bahwa saat ini dibutuhkkan organisasi ekstrakurikuler sekolah dalam meminimalkan perilaku sosial yang kurang baik di sekolah. Dari apa yang dilakukan oleh organisasi ekstrakurikuler Rohis setidaknya menggambarkan pada zaman sekarang ini nilai-nilai perilaku sosial yang baik perlu ditanam dan dijaga pada umat, terutama kalangan peserta didik. Penelitian ini menggunakan metode kuantitatif. Subjek penelitian sebanyak 36 responden. Jumlah responden diambil dari seluruh peserta didik yang mengikuti Rohis. Pengumpulan data menggunakan instrumen kuesioner yang berbentuk angket untuk menjaring data kegiatan Rohis dengan perilaku sosial peserta didik di SMA N 2 Puding Besar. Hasil penelitian ini menunjukan bahwa terdapat hubungan yang signifikan antara kegiatan Rohis dengan perilaku sosial peserta didik di SMA N 2 Puding Besar. Dibuktikan dengan hasil hitung nilai $r_{\text {hitung }>} r_{\text {tabel }}$ pada taraf signifikansi $1 \%$ yaitu nilai $r_{x y}=0,522>r_{\text {tabel }}=0,424$.
\end{abstract}

\begin{abstract}
The issue was taken based on the consideration that currently needed extracurricular school organizations in minimizing social behavior that is not good at school. From what is done by the Rohis extracurricular organization, at least it illustrates that in this day and age the values of good social behavior need to be planted and maintained in the community, especially among students. This research uses quantitative methods. Research subjects were 36 respondents. The number of respondents was taken from all students who followed Rohis. Data collection uses questionnaire instruments in the form of a questionnaire to capture data on Rohis activities and social behavior of students in SMA N 2 Puding Besar. The results of this study indicate that there is a significant relationship between Rohis activities and social behavior of students in SMA N 2 Puding Besar. Evidenced by the results of calculating the value of $r$ count $>r$ table at the significance level of $1 \%$, namely the value of $r x y=0.522>r$ table $=0.424$
\end{abstract}

\section{Koresponden:(9 pt)}

Beldi Akbar

Email: beldiakbar@gmail.com

This is an open access article distributed under the Creative Commons Attribution License, which permits unrestricted use, distribution, and reproduction in any medium, provided the original

\section{Pendahuluan}

Pendidikan merupakan sarana atau media yang akan mengantarkan peserta didik pada tujuan berakhlakul kharimah. Sarana dan prasarana tersebut dapat berupa fisik ataupun psikis. Sarana fisik meliputi pemenuhan kebutuhan makan, minum, pakaian, tempat tinggal, dan lain-lain. Sedangkan sarana psikis meliputi ketenangan, kebahagiaan, kasih sayang, ilmu pengetahuan duniawi dan keagamaan dan lain sebagainya. ${ }^{1}$ Oleh sebab itu, manusia sering disebut mahluk sosial, yaitu mahluk yang bergantung pada orang lain dalam segala hal pada kehidupan didunia ini.

\footnotetext{
1 Umiarso \& Zamroni, Pendidikan dan Pembebasan dalam Perspektif Barat dan Timur,(Jogjakarta: Ar-ruzz media, 2011), hlm. 80.
} 
Sebagai bangsa yang memiliki peradaban hidup tinggi, perilaku menjadi syarat penting dalam kehidupan sehari-hari. Menanamkan perilaku pada peserta didik adalah tugas berat yang harus dipikul bersama antara orang tua, guru, dan masyarakat secara umum. Demikian juga dengan peserta didik yang ada di sekolah, perilaku sosial peserta didik tidak terlepas dari bagaimana peserta didik tersebut berinteraksi sosial dengan lingkungannya. Peserta didik juga mempunyai sifat sosial dimana mereka membutuhkan teman, guru ataupun warga sekolah lainnya. Sebagai makhluk sosial yang beranjak dewasa atau dalam masa remaja tentu telah memperhatikan dan mengenal pergaulan umum yang berbeda dengan pergaulan yang berlaku didalam keluarga.

Pentingnya perilaku sosial peserta didik, yakni agar mereka dapat menanamkan sikap dan perilaku yang baik terhadap sesama individu yang lainnya. Kegiatan pembinaan dengan menerapkan perilaku sosial yang baik dapat membantu peserta didik dalam menunjang perkembangan minat, bakat, dan potensi peserta didik. Pendidikan dan pembinaan perilaku sosial dapat dimulai sejak seseorang sudah dapat menerima pengetahuan, baik secara pendidikan formal maupun pendidikan informal.

Peserta didik secara objek pendidikan harus dibina hingga dapat memiliki perilaku sosial yang baik. Perilaku sosial dapat diamati dari bagaimana peserta didik melakukan interaksi dengan gurunya, dengan lingkungannya, serta dengan sesama peserta didik. Perilaku sosial yang baik adalah seperti memberi salam ketika bertemu guru, menjaga hubungan keharmonisan hubungan antar peserta didik dengan peserta didik yang lain, dan menjaga lingkungan sekolah serta lingkungan kelas dengan tidak membuang sampah sembarangan. ${ }^{2}$ Beberapa contoh kecil diatas dapat dikategorikan perilaku sosial yang baik di dalam sekolah.

Berdasarkan observasi yang telah peneliti lakukan di SMA Negeri 2 Puding Besar, peneliti menemukan masalah umum peserta didik dalam berperilaku sosial misalnya seperti menggunakan bahasa daerah yang kurang tepat kepada guru dan terkesan kurang menghormati, kadang-kadang tidak mengucapkan salam dan bersalaman dengan gurunya ketika bertemu, ribut sendiri ketika Kegiatan Belajar Mengajar (KBM) berlangsung, kadang-kadang terjadi pertengkaran antar peserta didik, ada semacam kelompok tertentu yang menyebabkan saling bermusuhan, dan peserta didik menggunakan bahasa daerah yang kasar ketika berinteraksi dengan peserta didik lain.

Sehubungan dengan hal-hal yang sudah dijelaskan di atas, kegiatan organisasi yang dapat membina perilaku sosial peserta didik dirasa penting untuk dilakukan. Oleh karena itu, diperlukan suatu kegiatan ekstrakurikuler di sekolah agar dapat membantu peserta didik dalam berinteraksi dengan orang lain agar dapat menampilkan atau menonjolkan suatu hal yang positif didalam dirinya. Kegiatan ekstrakurikuler ini adalah Rohis. Keberadaan kegiatan rohis ini diharapkan dapat membantu peserta didik dalam mengaplikasikan suatu perilaku sosial yang positif dan dapat menjadi cerminan untuk peserta didik lain yang melihatnya. Pada dasarnya penyelenggaraan ekstrakurikuler di sekolah bertujuan menggali dan memotivasi siswa-siswa pada bidang tertentu. Karena itu aktivitas ekstrakurikuler harus disesuaikan dengan hobi dan kondisi siswa, sehingga melalui kegiatan tersebut siswa dapat memperjelas identitas dirinya. Kegiatan itupun harus ditunjukan untuk membangkitkan semangat dinamika dan optimis peserta didik sehingga mereka mencintai sekolahnya dan menyadari posisinya ditengah-tengah masyarakat. ${ }^{3}$

Kegiatan-kegiatan yang dilaksanakan Rohis mencakup dari segi agama Islam. Membahas tentang masalah-masalah agama seperti belajar mengaji, belajar sholat dengan baik, sampai kepada mempelajari tentang syari'at agama Islam. ${ }^{4}$ Tidak terlepas dari semua hal diatas kegiatan ekstrakurikuler ini sangat penting dikarenakan diantara aktivitas yang dilakukan juga terdapat bagaimana peserta didik mampu bekerja sama dalam hal apapun dan menonjolkan bakat-bakatnya kepada orang lain dalam hal berbicara didepan umum, berperilaku sosial yang baik dan dapat menghargai satu sama lain. Inilah yang menjadi dampak positif ketika kita mengikuti suatu organisasi.

Dari latar belakang diatas, peneliti menyadari betapa pentingnya rohis dalam meningkatkan pemahaman agama dan berperilaku sosial yang baik terutama didalam sekolah. Mengingat pemahaman agama ini begitu penting untuk bekal akhirat kita dan perilaku sosial kita terhadap orang lain agar kita terhindar dari sifat yang sombong, juga dapat mempengaruhi kita dalam hal berinteraksi dengan orang lain.

Rohis merupakan singkatan dari Rohani Islam. Koesmarwanti dan Nugroho Widiyantoro menyebutkan kata Rohani Islam ini sering disebut dengan istilah 'rohis' yang berarti sebagai suatu wadah besar yang dimiliki oleh siswa untuk menjalankan aktivitas dakwah di sekolah. ${ }^{5}$ Sedangkan Badrudin mengatakan bahwa rohis adalah suborganisasi dari organisasi siswa intra sekolah yang kegiatannya

2 Saifuddin Amin, Etika Peserta Didik Menurut Syaikh Muhammad bin Shalih Al-Utsaimin, (Yogyakarta: Deepublish, 2019), h1m. 27.

${ }^{3}$ Abdurrahman An-Nahlawi, Pendidikan Islam di Rumah, Sekolah, dan Masyarakat, terj. Dari 'Ushulut Tarbiyah Islamiyah Wa Madrasati Mujtama' oleh Shihabuddin, (Jakarta: Gema Insani Pers, 1995), hlm. 187.

${ }^{4}$ Yaqub, Ketua Rohis SMA N 2 Puding Besar, Wawancara, 11 maret 2019 pukul 15.30 WIB.

${ }^{5}$ Koesmarwanti, Dakwah Sekolah di Era Baru, (Solo: Era Inter Media, 2000), hlm. 124. 
mendukung intrakurikuler keagamaan dengan memberikan pendidikan, pembinaan dan pengembangan potensi peserta didik muslim agar menjadi insan yang beriman, bertakwa kepada Tuhan yang maha esa dan berakhlak mulia dengan mengimplementasikan ajaran Islam dalam kehidupan sehari-hari. ${ }^{6}$

Berdasarkan kedua teori diatas dapat disimpulkan bahwa rohis adalah organisasi intra sekolah yang berkaitan kepada keagamaan Islam sebagai aktivitas dakwah yang dapat memberikan pendidikan, pembinaan dan pengembangan peserta didik. Rohis sendiri memiliki manfaat tersendiri untuk anggota yang mengikuti ekstrakurikuler yang berada disekolah tersebut, terutama mengajak kepada kebaikan dengan agenda-agenda yang bermanfaat. ${ }^{7}$ Dengan demikian peserta didik yang mengikuti kegiatan rohis segala kegiatannya terisi dengan hal-hal yang bermanfaat dan menambah wawasan serta jiwa religius.

Menurut Kamus Besar Bahasa Indonesia, perilaku adalah tanggapan atau reaksi individu terhadap rangsangan atau lingkungan. ${ }^{8}$ Sedangkan sosial adalah sesuatu yang berkenaan dengan masyarakat. ${ }^{9}$ Perilaku sosial adalah aktifitas fisik dan psikis seseorang terhadap orang lain atau sebaliknya dalam rangka memenuhi diri atau orang lain yang sesuai dengan tuntutan sosial. ${ }^{10}$

Dipandang dari aspek biologis perilaku adalah suatu kegiatan atau aktivitas organisme atau mahkluk hidup yang bisa dilihat sedangkan perilaku manusia pada hakikatnya adalah tindakan atau aktivitas dari manusia itu sendiri yang mempunyai bentangan yang sangat luas antara lain berjalan, berbicara, menangis,tertawa, membaca dan sebagainya, sehingga dapat disimpulkan bahwa perilaku manusia adalah semua kegiatan atau aktivitas manusia baik yang dapat diamati secara langsung maupun yang tidak secara langsung. ${ }^{11}$

Mark weber mengemukakan bahwa perilaku merupakan suatu perubahan dalam menghadapi reaksi sosial dilingkungan masyarakat dan dapat memberikan informasi bagaimana peran suatu perilaku itu terhadap lingkungan dan individu atau organisme yang bersangkutan sehingga perilaku juga mempengaruhi individu itu sendiri disamping itu juga berpengaruh terhadap lingkungan. ${ }^{12}$

Dari pendapat diatas dapat disimpulkan bahwa perilaku adalah suatu tingkah laku individu didalam atau disaat individu tersebut berinteraksi dengan orang lain baik secara langsung maupun tidak langsung. Sedangkan sosial adalah lingkungan, dimana seorang individu sangat bergantung sekali terhadap pembentukan tingkah lakunya. Perilaku sosial adalah aktifitas fisik dan psikis seseorang terhadap orang lain atau sebaliknya dalam rangka memenuhi diri atau orang lain yang sesuai dengan tuntutan sosial. ${ }^{13}$ Perilaku tersebut dapat menjadi tolak ukur seseorang dalam menjalani kehidupan. Oleh karena itu perilaku menjadi penting sekali di kehidupan.

Aspek-aspek perilaku meliputi pengamatan, perhatian, fantasi, ingatan, tanggapan dan berpikir yakni akan dijelaskan sebagai berikut.

a. Pengamatan merupakan kegiatan untuk mengenal obyek menggunakan panca indra, dengan jalan melihat, mendengar, meraba, membau dan mengecap.

b. Perhatian merupakan kegiatan pemusatan energi psikis yang tertuju pada obyek secara sadar.

c. Fantasi merupakan kemampuan membentuk tanggapan yang telah ada yang menunjukan kreativitas.

d. Ingatan merupakan aspek perilaku sehingga orang dapat merefleksi dirinya.

e. Tanggapan merupakan reaksi atas informasi pada seseorang dan berbeda-beda tergantung dari hangat tidaknya, hidup hampanya, sensualitas atau spiritualitas, lahiriah atau batiniah yang akan memengaruhi perilaku seseorang.

f. Asosiasi merupakan hubungan antara tanggapan yang satu dengan yang lainnya saling mereproduksi.

g. Berpikir merupakan aktifitas idealistis menggunakan simbol-simbol dalam memecahkan masalah berupa deretan ide dan bentuk bicara. ${ }^{14}$

\section{Metode}

\footnotetext{
6 Badrudin, Manajemen Peserta Didik,. (Jakarta: Indeks, 2014), hlm. 163-164.

7 Badruz Zaman, Pelaksanaan Mentoring Ekstrakurikuler Rohani Islam (ROHIS) dalam Meningkatkan Kecerdasan Spiritual Siswa Kelas X di SMA N 3 Boyolali Tahun Ajaran 2015/2016, Jurnal, (Salatiga: Fakultas Tarbiyah Jurusan PAI IAIN Salatiga, 2017), Hlm. 148.

8 DEPENAS, Kamus Besar Bahasa Indonesia, (Jakarta: Balai Pustaka, 2002), hlm. 88.

9 Ibid., hlm. 912.

10 Abu Ahmadi, Psikologi Sosial, (Jakarta: RinekaCipta, 2000), hlm. 38.

${ }^{11}$ Notoatmodjo, Pendidikan dan Perilaku Kesehatan, (Jakarta: Rineka Cipta, 2006), hlm. 35.

12 Salim Agus, Perubahan Sosial, (Yogyakarta: PT Tiara Wacana, 2002), hlm. 37.

${ }^{13}$ Hurlock, E, B, Psikologi Perkembangan: suatu pendekatan sepanjang rentang kehidupan, (Jakarta: Erlangga, 2007), hlm. 262.

${ }^{14}$ Aisyah, Perkembangan Peserta Didik \& Bimbingan Belajar, (Yogyakarta: Deepublish, 2015), hlm. 2.
} 
Penelitian ini menggunakan pendekatan kuantitatif dan studi korelasional kuantitatif. Penelitian ini meneliti tentang hubungan antara variabel yang satu dengan variabel yang lain. Penelitian ini mempunyai dua variabel yaitu hubungan mengikuti kegiatan kerohanian Islam sebagai variabel X dan perilaku sosial peserta didik sebagai variabel Y. Penelitian ini dilaksanakan di SMA Negeri 2 Puding Besar pada tahun 2019. Waktu penelitian akan dilaksanakan dari sejak dikeluarkannya surat izin penelitian oleh Rektor IAIN Syaikh Abdurrahman Siddik Bangka Belitung sampai dengan selesai.

Populasi dalam penelitian ini adalah semua peserta didik yang tergabung dalam kegiatan kerohanian Islam di SMA Negeri 2 Puding Besar yakni 40 orang. Sampel diambil dari populasi semua peserta didik yang mengikuti kegiatan rohis. Untuk itu peneliti mengambil sampel dengan cara sensus. Dengan kata lain peneliti menggunakan sampling jenuh. Adapun sampling jenuh yaitu teknik penentuan sampel bila semua anggota populasi digunakan sebagai sampel. Berdasarkan sumbernya, data penelitian ini bisa dikelompokkan ke dalam dua jenis, yaitu sumber data primer dan sumber data sekunder. Pengumpulan data dilakukan dengan angket yang telah tervalidasi terlebih dahulu kemudian data diolah menggukana apikasi SPSS.

\section{Hasil dan Pembahasan}

Setelah mengetahui hasil jawaban responden melalui penyebaran kuesioner kegiatan rohis, maka peneliti menyajikan data dalam bentuk tabel statistik untuk variabel $\mathrm{X}$.

\section{Variabel X}

\begin{tabular}{|l|r|}
\hline N $\quad$\begin{tabular}{r}
\multicolumn{1}{|c|}{ Valid } \\
\multicolumn{1}{|c}{ Missing }
\end{tabular} \\
Mean & 0 \\
Median & 61.86 \\
Mode & 60.50 \\
Std. Deviation & 59 \\
Variance & 5.178 \\
Range & 26.809 \\
Minimum & 26 \\
Maximum & 52 \\
Sum & 78 \\
\hline
\end{tabular}

Dari tabel kegiatan rohis (variabel X), maka diperoleh rentang skor minimum 52 dan skor maksimum 78. Skor rata-rata mean diperoleh sebesar 61,86. Skor frekuensi tengah diperoleh sebesar 60,50. Dan skor frekuensi tertinggi (modus) diperoleh sebesar 59. Dari data tersebut diperoleh simpangan baku yakni sebesar 5,178. Kemudian setelah mengetahui hasil jawaban responden melalui penyebaran kuesioner Perilaku sosial peserta didik, maka peneliti menyajikan data dalam bentuk tabel statistik untuk variabel Y. 


\section{Variabel Y}

\begin{tabular}{|l|r|}
\hline N $\quad$ Valid & 36 \\
Mean & 0 \\
Median & 60.44 \\
Mode & 60.00 \\
Std. Deviation & 59 \\
Variance & 6.002 \\
Range & 36.025 \\
Minimum & 34 \\
Maximum & 43 \\
Sum & 77 \\
\hline
\end{tabular}

Dari hasil perhitungan angket yang berisi 16 item pernyataan yang lolos, diperoleh rentang skor minimum 43 dan skor maksimum 77. Skor frekuensi rata-rata (mean) adalah 60,44. Skor frekuensi tengah (median) diperoleh 60,00. Skor frekuensi tertinggi (modus) diperoleh sebesar 59. Dari data tersebut diperoleh skor frekuensi variance sebesar 36,025. Skor frekuensi range (rentang skor) diperoleh sebesar 34, dan skor frekuensi dari simpangan baku diperoleh yakni sebesar 6,002

\section{Uji Normalitas}

\begin{tabular}{|ll|r|}
\hline \multicolumn{2}{|c|}{ One-Sample Kolmogorov-Smirnov Test } \\
\hline $\mathrm{N}$ & $\begin{array}{c}\text { Unstandardized } \\
\text { Residual }\end{array}$ \\
Normal Parameters ${ }^{\mathrm{a}}$ & Mean & 36 \\
& Std. Deviation & .0000000 \\
Most Extreme Differences & Absolute & 5.11798781 \\
& Positive & .175 \\
& Negative & .093 \\
Kolmogorov-Smirnov Z & & -.175 \\
Asymp. Sig. (2-tailed) & & 1.047 \\
& & .223 \\
\hline
\end{tabular}

Berdasarkan hasil perhitungan Kolmogorov-Smirnov diperoleh nilai sinifikansi 0,223 artinya nilai tersebut lebih besar dari nilai taraf signifikan 0,05. Hal ini menunjukan bahwa seluruh variabel berdistribusi normal.

1. Uji Linearitas

Hasil Pengujian Linearitas Variabel X terhadap Variabel Y

\section{Tabel XI}

Uji Linearitas Variabel X terhadap Variabel Y 


\begin{tabular}{|c|c|c|c|c|c|c|c|}
\hline \multicolumn{8}{|c|}{ ANOVA Table } \\
\hline & & & \begin{tabular}{|l|} 
Sum of \\
Squares
\end{tabular} & $\mathrm{df}$ & $\begin{array}{l}\text { Mean } \\
\text { Square }\end{array}$ & F & Sig. \\
\hline \multirow[t]{5}{*}{$\begin{array}{l}\text { VARIABEL_Y }{ }^{*} \\
\text { VARIABEL_X }\end{array}$} & \multicolumn{2}{|c|}{$\begin{array}{l}\text { Between (Combined } \\
\text { Groups ) }\end{array}$} & & 16 & & & \\
\hline & & Linearity & 344.106 & 1 & 344.106 & 10.018 & .005 \\
\hline & & $\begin{array}{l}\text { Deviation } \\
\text { from } \\
\text { Linearity }\end{array}$ & 264.154 & 15 & 17.610 & .513 & .903 \\
\hline & Within G & roups & 652.629 & 19 & 34.349 & & \\
\hline & Total & & 1260.88 & 35 & & & \\
\hline
\end{tabular}

Berdasarkan hasil perhitungan uji linearitas diketahui Sig sebesar 0,903 $>0,05$. Maka dapat disimpulkan bahwa terdapat hubungan yang linear antara variabel $\mathrm{X}$ dengan $\mathrm{Y}$. Hubungan antara variabel yaitu kegiatan rohis (variabel X) dan perilaku sosial peserta didik (variabel Y) divari dengan menggunakan rumus product moment. Hasil perhitungan menghasilkan nilai $r$. Nilai koefisien korelasi $(r)$ hasil perhitungan kemudian dikonsultasikan dengan $r_{\text {tabel. }}$. Nilai $r$ tabel untuk sampel 36 dengan taraf signifikan $1 \%$ yaitu 0,424. Jika $r_{\text {hitung }}>r_{\text {tabel }}$ maka terdapat pengaruh positif antara variabel $\mathrm{x}$ dan $\mathrm{y}$. Jika $\mathrm{r}_{\text {hitung }}<$ $\mathrm{r}_{\text {tabel }}$ maka terdapat pengaruh negatif antara variabel $\mathrm{x}$ dan $\mathrm{y}$. Sedangkan perhitungan menggunakan rumus product moment sebagai berikut.

perhitungan selanjutnya akan dikonsultasikan dengan $r_{\text {tabel. }}$ Jika $r_{\text {hitung }}<r_{\text {tabel }}$ berarti hasil perhitungan antara variabel $\mathrm{X}$ dan $\mathrm{Y}$ tidak signifikan antara kegiatan rohis dengan perilaku sosial peserta didik di SMA N 2 Puding Besar. Dengan demikian Hipotesis yang peneliti ajukan ditolak. Dengan demikian, karena nilai $\mathrm{r}_{\mathrm{xy}}=0,522>\mathrm{r}_{\text {tabel }}=0,424$ pada taraf signifikansi $1 \%$. Maka dengan ini dapat disimpulkan bahwa $\mathrm{H}_{0}$ (hipotesis kerja) diterima. Dengan demikian terdapat hubungan yang signifikan antara kegiatan rohis dengan perilaku sosial peserta didik di SMA N 2 Puding Besar.Kemudian dari hasil pedoman derajat hubungan nilai $\mathrm{r}_{\mathrm{xy}}$ terletak antara nilai pearson correlation 0,41 s/d 0,60 berarti dapat diketahui bahwa hubungan antara kegiatan rohis dengan perilaku sosial peserta didik di SMA N 2 Puding Besar memiliki tingkat korelasi sedang.

\section{Kesimpulan}

Dari uraian diatas maka peneliti dapat menarik kesimpulan yang juga merupakan jawaban dari tiga pertanyaan yang diajukan dalam penelitian ini, ketiga kesimpulan tersebut adalah sebagai berikut: 1) Berdasarkan analisis deskriptif, melalui program SPSS 16.0 dapat diketahui bahwa variabel kegiatan rohis adalah sebagai berikut: 2) Mengenai kategori perilaku sosial peserta didik di SMA N 2 Puding Besar adalah sebagai berikut: 3) Ada hubungan yang signifikan antara kegiatan rohis dengan perilaku sosial peserta didik di SMA N 2 Puding Besar. Dengan demikian, hipotesis alternatif $\left(\mathrm{H}_{\mathrm{a}}\right)$ dapat diterima dan hipotesis nihil $\left(\mathrm{H}_{0}\right)$ ditolak. Hal ini dibuktikan dengan nilai $\mathrm{r}_{\text {hitung }>} \mathrm{r}_{\text {tabel }}$ pada taraf signifikansi $1 \%$ yaitu nilai $\mathrm{r}_{\mathrm{xy}}=$ $0,522>\mathrm{r}_{\text {tabel }}=0,424$.

\section{Referensi}

Agus, Salim. 2002. Perubahan Sosial. Yogyakarta: PT Tiara Wacana.

Ahmadi, Abu. 2000. Psikologi Sosial. Jakarta: RinekaCipta.

Aisyah. 2015. Perkembangan Peserta Didik \& Bimbingan Belajar. Yogyakarta: Deepublish.

Amin, Saifuddin. 2019. Etika Peserta Didik Menurut Syaikh Muhammad bin Shalih Al-Utsaimin. Yogyakarta: Deepublish.

An-Nahlawi, Abdurrahman. 1995. Pendidikan Islam di Rumah, Sekolah, dan Masyarakat, terj. Dari 'Ushulut Tarbiyah Islamiyah Wa Madrasati Mujtama' oleh Shihabuddin. Jakarta: Gema Insani Pers.

Arikunto. 2005. Manajemen Penelitian. Jakarta: Rineka Cipta.

Badrudin. 2014. Manajemen Peserta Didik. Jakarta: Indeks. 
Bahri, Syaiful. 2008. Psikologi Belajar. Jakarta: PT Rineka Cipta.

Bungin, Burhan. 2005. Metodologi Penelitian Kuantitatif. Jakarta: Kencana

Byrne \& Baron. 2004. Psikologi sosial jilid 1. Jakarta: Erlangga.

Daud Ali, Mohammad. 2006. Pendidikan Agama Islam. Jakarta: PT Rajagrafindo Persada.

DEPENAS. 2002. Kamus Besar Bahasa Indonesia. Jakarta: Balai Pustaka.

Fahrozi, Muhammad. 2004. Pemahaman Tingkah Laku. Jakarta: Asdi Mahasatya.

Hanifah, Ummu. 2015 "Pengaruh Keikutsertaan Siswa dalam Organisasi Kerohanian Islam (ROHIS)

terhadap Perilaku Keagamaan Siswa SMA Negeri 1 Sragen", Skripsi. Semarang: Fakultas Tarbiyah Jurusan PAI UIN Walisongo.

Hurlock, E, B. 2007. Psikologi Perkembangan: suatu pendekatan sepanjang rentang kehidupan. Jakarta: Erlangga.

Jalaluddin. 2011. Psikologi Agama. Jakarta: Raja Grafindo Persada.

Koesmarwanti. 2000. Dakwah Sekolah di Era Baru. Solo: Era Inter Media.

Latif, Abdul. 2007. Pendidikan Berbasis Nilai Kemasyarakatan. Bandung: PT Refika Aditama

Mahmud. 2015. Pendidikan Lingkungan Sosial Budaya. Bandung: PT Remaja Rosdakarya.

Margono. 2005. Metodologi Penelitian Pendidikan. Jakarta: Rineka Cipta.

Mashudi, Farid. 2012. Psikologi Konseling. Yogyakarta: IRCiSoD.

Muchlas. 2005. Perilaku Organisasi. Yogyakarta: Gadjah Mada University Press.

Mudyahardjo, Redja. 2014. Pengantar Pendidikan. Jakarta: PT RajaGrafindo Persada.

Nitimiharjo, Carolina. 1983. Psikologi sosial. Bandung: senat mahasiswa sekolah tinggi kesejahteraan sosial.

Notoatmodjo. 2006. Pendidikan dan Perilaku Kesehatan. Jakarta: Rineka Cipta.

Sambas Ali Muhidin, dan Maman Abdurrahman. 2007. Analisis Korelasi, Regresi, dan Jalur dalam Penelitian. Bandung: CV Pustaka Setia.

Setiono, Kusdwiratri. 2011. Psikologi Belajar. Jakarta: PT Alumni.

Slameto. 2003. Belajar dan faktor-faktor yang mempengaruhinya. Jakarta: Rineka cipta.

Soedarmanta. 2010. Membiasakan perilaku yang terpuji. Jakarta: PT GRASINDO.

Sugiyono. 2015. Metode Penelitian Pendidikan. Bandung: ALFABETA.

Suhada, Idad. 2016. Ilmu Sosial Dasar. Bandung: PT Remaja Rosdakarya.

Suharsimi, Arikunto. 2005. Manajemen Penelitian. Jakarta: Rineka Cipta.

Suharsimi, Arikunto. 2006. ProsedurPenelitian. Jakarta: PT Rineka Cipta.

Sumanto. 2014. Teori dan Aplikasi Metode Penelitian "Psikologi, Pendidikan, Ekonomi, Bisnis, dan Sosial. Yogyakarta: Center Of Academic Publishing Service.

Sunarto dan Riduwan. 2011. Pengantar Statistika Untuk Penelitian Pendidikan, Sosial, Ekonomi Komunikasi, dan Bisnis. Bandung: Alfabeta.

Surya, Mohamad. 2014. Psikologi Guru Konsep dan Aplikasi. Bandung: Alfabeta.

Thoha, Miftah. 2014. Perilaku Organisasi; Konsep Dasar dan Aplikasinya. Jakarta: Rajawali Pers.

Umiarso \& Zamroni. 2011. Pendidikan dan Pembebasan dalam Perspektif Barat dan Timur. Jogjakarta: Arruzz media.

Wahyudi. 2013. "Hubungan antara Keaktifan Dalam Mengikuti Kegiatan ROHIS dengan Kesalehan Sosial pada anggota ROHIS SMA Negeri 2 Sleman", Skripsi. Yogyakarta: Fakultas Tarbiyah Jurusan PAI UIN Sunan Kalijaga.

Wasis dan Yulingga. 2017. Statistika Pendidikan. Yogyakarta: Deepublish.

Yaqub, Ketua Rohis SMA N 2 Puding Besar, Wawancara, 11 maret 2019 pukul 15.30 WIB.

Yusuf, Syamsu. 2011. Psikologi perkembangan anak dan remaja. Bandung: PT Remaja Rosdakarya

Zaman, Badruz. 2017. Pelaksanaan Mentoring Ekstrakurikuler Rohani Islam (ROHIS) dalam Meningkatkan Kecerdasan Spiritual Siswa Kelas X di SMA N 3 Boyolali Tahun Ajaran 2015/2016, Jurnal. Salatiga: Fakultas Tarbiyah Jurusan PAI IAIN Salatiga. 